\title{
THE GEOMETRY OF THE HUMERAL HEAD AND THE DESIGN OF PROSTHESES
}

\author{
SIMON N. J. ROBERTS, ANDREW P. J. FOLEY,
}

HEATHER M. SWALLOW, W. ANGUS WALLACE, DAVID P. COUGHLAN

\author{
From the University of Nottingham
}

\begin{abstract}
The articular surface of the humeral head is usually described as facing posteromedially, making an angle of between $16^{\circ}$ and $35^{\circ}$ with the transepicondylar plane. At hemiarthroplasty the articular surface also appears to be ofiset posteriorly with respect to the humeral shaft. Coracoid impingement may occur if this ofiset is not accommodated.

An analysis was made of 29 cadaveric humeri using an industrial co-ordinate measuring machine. The position of the centre of the head was defined with respect to the humeral shaft and transepicondylar plane. The humeral articular surface was found to be retroverted by $21.4^{\circ}$ and its centre ofiset posteriorly by $4.7 \mathrm{~mm}$.

Previous interpretation of retroversion did not take into account the posterior displacement, and this may be of importance in improving future prosthetic design.
\end{abstract}

The articular surface of the humeral head is usually described as facing superiorly at $135^{\circ}$ to the shaft as well as posteromedially, making an angle estimated at between $16^{\circ}$ and $35^{\circ}$ with the transepicondylar plane (Inman, Saunders and Abbott 1944; Neer 1955, 1974; Williams and Warwick 1980; Kapandji 1982). The senior author's clinical experience with shoulder arthroplasty (WAW) suggests that the humeral head may be offset posteriorly so that its centre may lie significantly behind the axis of the shaft of the humerus, and that the heads of currently available prostheses lie anterior to the bone which they replace (Fig. 1). This would indicate that humeral prostheses need modification in design to produce a more anatomical configuration.

Surface measurements were made on 39 human cadaveric humeri using an industrial co-ordinate measuring machine. The collected data were applied to software programs for geometric fitting in relation to the

S. N. J. Roberts, BM BCh, Senior House Officer

H. M. Swallow, BM BS, Senior House Officer

W. A. Wallace, FRCS Ed(Orth), Professor

Department of Orthopaedic and Accident Surgery, University Hospital, Queen's Medical Centre, Nottingham NG7 2UH, England.

A. P. J. Foley, M Eng, Postgraduate Research Student

Department of Production Engineering, University of Nottingham, University Park, Nottingham NG7 2RD, England.

D. P. Coughlan, Northern Sales Manager

Mitutoyo (UK) Ltd, Unit 5-6 Enterprise Park Industrial Estate, Morehouse Avenue, Old Lane, Beeston, Leeds LS11 8HA, England.

Correspondence should be sent to Dr S. N. J. Roberts.

(C) 1991 British Editorial Society of Bone and Joint Surgery

$0301-620 X / 91 / 4133 \$ 2.00$

J Bone Joint Surg [Br] 1991 ; 73-B : 647-50. humeral shaft and the transepicondylar plane. The position and orientation of the segment of the sphere represented by the articular surface was computed for each specimen.

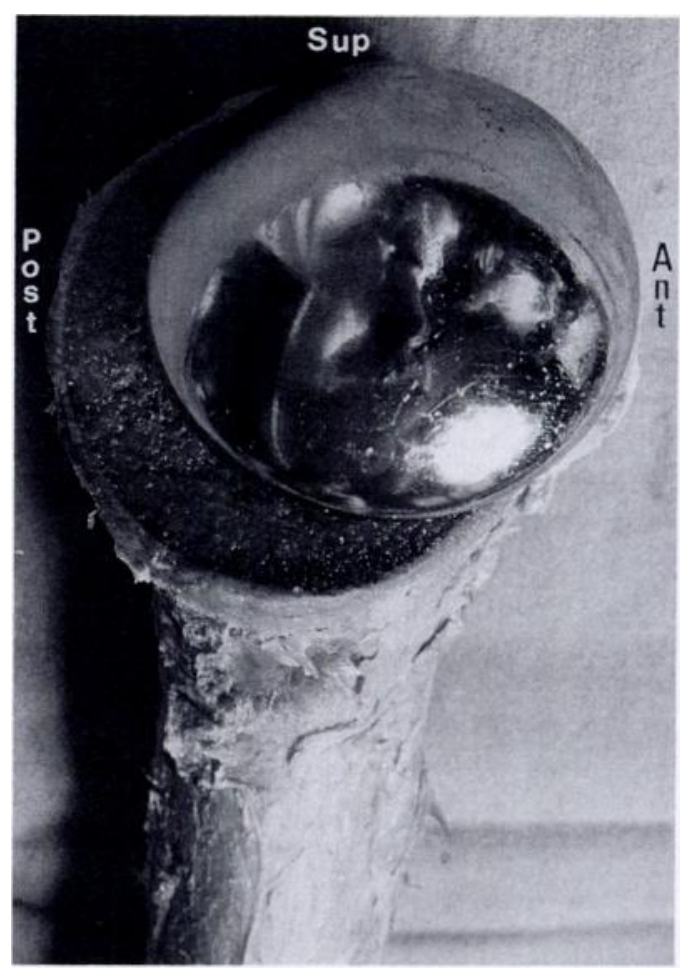

Fig. 1

Medial aspect of the humeral neck with a standard prosthesis located in line with the shaft. 


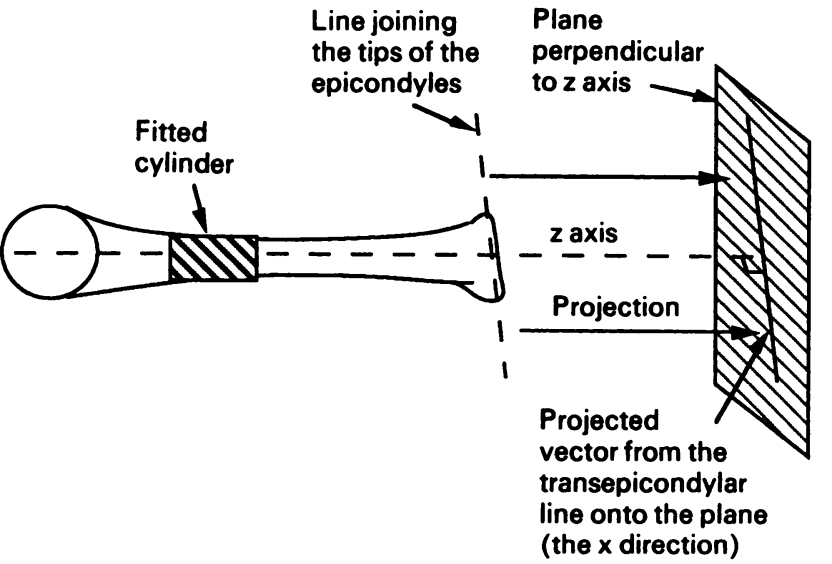

Fig. 2

Diagram showing the method used to define the $\mathrm{X}$ direction.

\section{MATERIALS AND METHODS}

Embalmed cadaveric humeri (19 left, 20 right) were obtained and carefully dissected of all soft tissue, avoiding damage to the articular cartilage.

The co-ordinate measuring machine has an almost frictionless, three-axis gantry allowing a stylus to be moved to any position, the co-ordinates of which are measured with respect to the machine's own frame of reference. Its accuracy (in the order of $10 \mu \mathrm{m}$ ) is such that the margin of error may be considered insignificant for this application.

We defined our axis system in the anatomical planes and then took points on the articular surface for analysis using the Mitutoyo B706 co-ordinate measuring machine and the accompanying Geopak-2 v6.3 manual software.

Definition of axes. Twenty points were taken arbitrarily on the cleaned periosteum of the proximal half of the shaft of the humerus avoiding the deltoid tuberosity and bicipital groove. The 'best fit' cylinder was calculated for these points and its axis taken to define the shaft axis ( $Z$ in Fig. 2). A point was taken at the most medial and the most lateral extremity of the distal humerus to define the transepicondylar line. The projection of this line onto the plane perpendicular to the already defined axis $\mathrm{Z}$ resulted in a vector which defined the $X$ co-ordinate direction in our analysis. The $\mathrm{Y}$ direction was taken perpendicular to the $\mathrm{X}-\mathrm{Z}$ plane, and the two orthogonal directions and the defined axis $Z$ were used to establish a cartesian coordinate axis system, with an origin arbitrarily selected to lie within the cylinder. The positive directions for $\mathrm{X}$, $\mathrm{Y}$ and $\mathrm{Z}$ were medial, posterior and superior respectively. Centre of curvature and diameter. Twelve points were taken arbitrarily on the hyaline cartilage of the humeral head and a sphere was fitted to these points the diameter and centre of which were calculated.

Orientation. Five points were taken on the periphery of the articular surface and the 'best fit' plane calculated, along with its orientation with respect to the $\mathrm{X}-\mathrm{Z}$ and

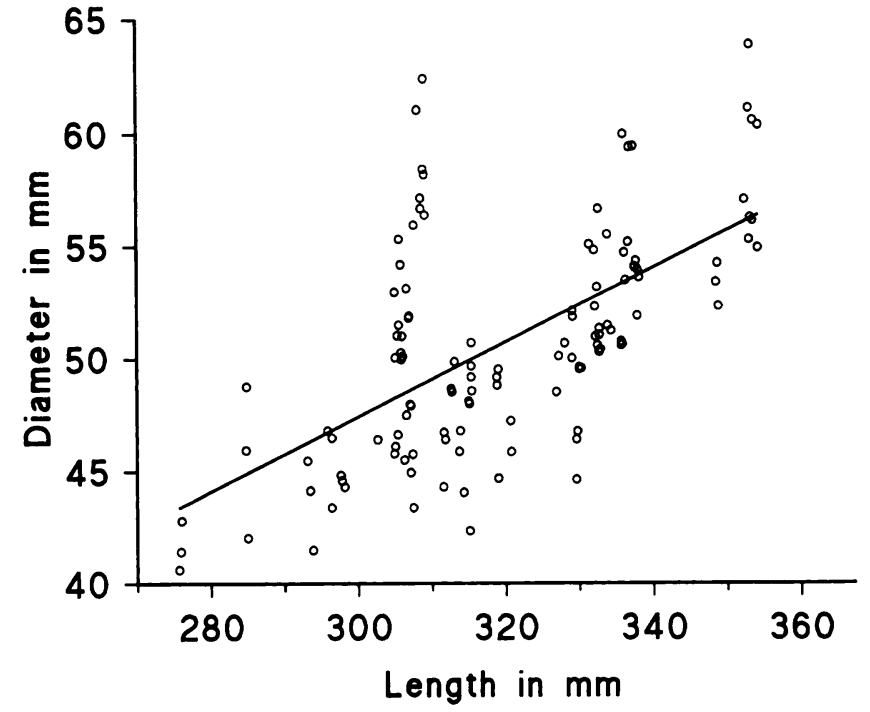

Fig. 3

Relationship between the length of the bone and the diameter of the humeral head.

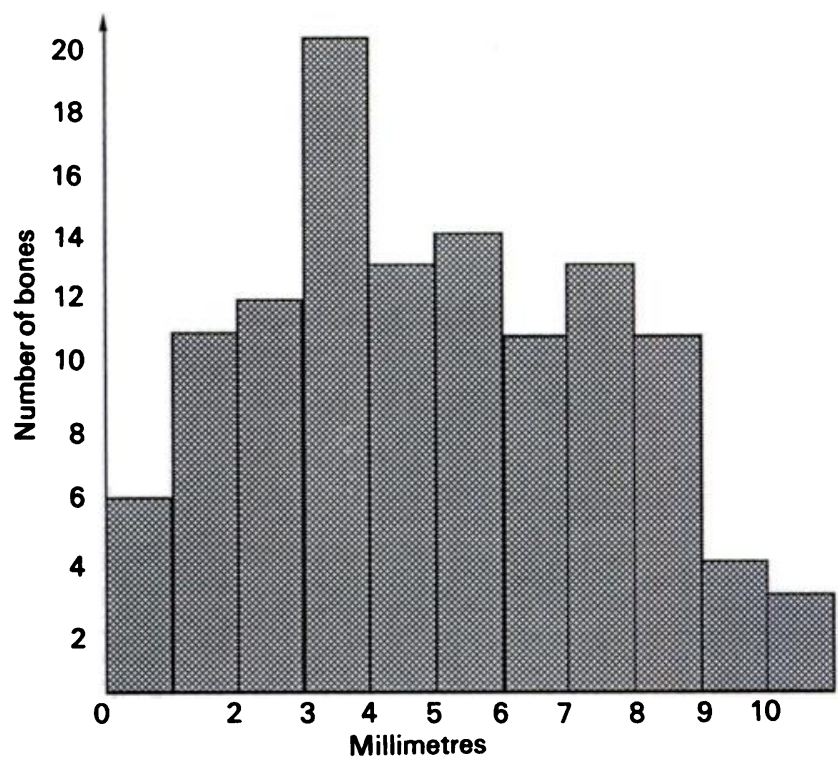

Fig. 4

Posterior offset of centre of humeral head from shaft.

$\mathrm{X}-\mathrm{Y}$ planes thus giving the orientation of the segment of the sphere represented by the joint surface.

Length of the bone. Points were taken at the most superior and inferior points on the bone and their separation calculated.

\section{RESULTS}

The 39 humeri were analysed a total of 124 times including one bone which was analysed ten times as a methodological control. Figure 3 shows the relationship between the length of the bone and the diameter of the 


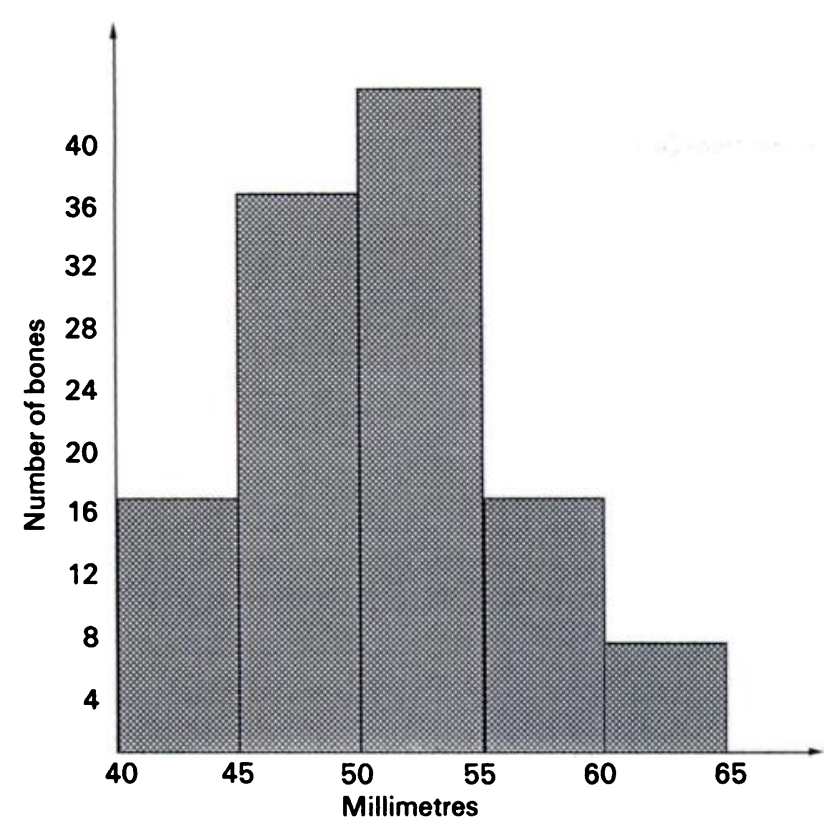

Fig. 5

Diameter of the humeral head.

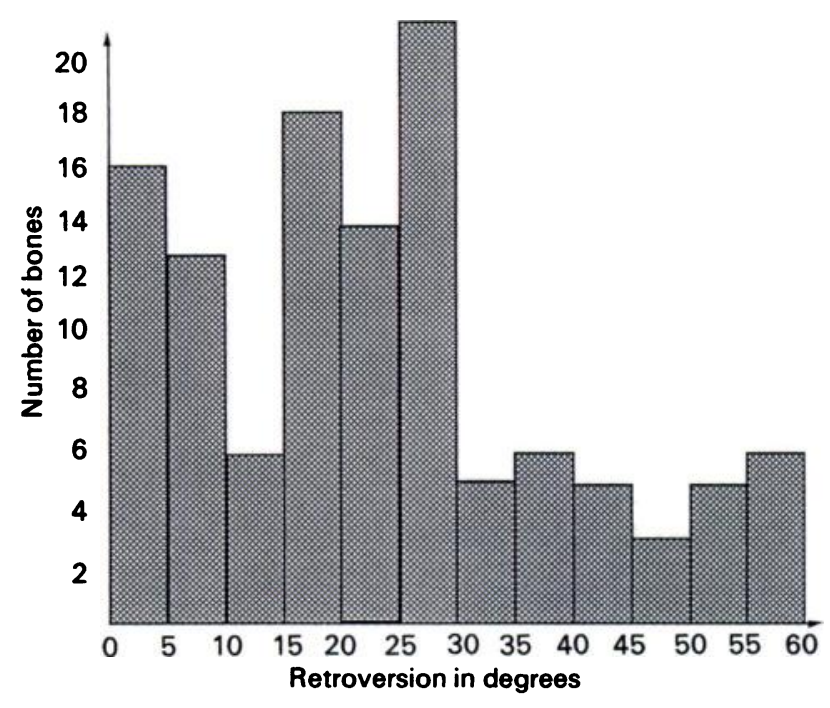

Fig. 6

Angle of retroversion in relation to the transepicondylar line.

humeral head (correlation coefficient 0.615 ). Figure 4 shows the distribution of the posterior $(\mathrm{Y})$ displacement of the centre of the sphere fitted to the articular surface in millimetres. The spread of results was not improved when corrected for the size of the humeral head. All 39 measured bones demonstrated an offset and its median value was $4.7 \mathrm{~mm}$ with a $95 \%$ confidence interval of 4.0 to $5.5 \mathrm{~mm}$ using a non-parametric analysis $\mathrm{N}_{0.975}$ (Campbell and Gardner 1988). The measured diameters in millimetres are shown in Figure 5, median $50.3 \mathrm{~mm}$, $95 \%$ confidence limit 49.6 to $51.1 \mathrm{~mm}$.

Figure 6 shows the retroversion (with respect to the transepicondylar line) of the plane fitted to a set of points taken on the periphery of the articular cartilage. The median retroversion was $21.4^{\circ}(95 \%$ confidence limit, $18.5^{\circ}$ to $25.0^{\circ}$ ). The standard deviations for one bone measured ten times were calculated for offset, diameter and retroversion and were found to be $7 \%, 3.4 \%$ and $4 \%$ of the mean, indicating a high degree of reproducibility.

In order to gain an indication of the adequacy of the geometric modelling technique, the maximum deviation of the measured point from the fitted geometric entity was recorded. For the cylinder, the ratio (maximum deviation: diameter of the cylinder) averaged $11 \%$, though for one bone this ratio was as high as $25 \%$ suggesting that fitting a cylinder to the data collected along the shaft in this bone was a poor model. By contrast, the same ratio applied to the spherical model of the humeral head averaged $1 \%$. Therefore, a sphere appears to be a good representation of the geometry of this part of the bone.

\section{DISCUSSION}

Our intention was to locate the centre of curvature of the humeral head with respect to the stem of an inserted prosthesis, and its orientation with respect to surgically useful landmarks. The variable geometry of the humeroulnar joint has been described (Amis et al 1977; Shiba et al 1988), and although a jig has been suggested (Ovesen, Sojbjerg and Sneppen 1987), in practice a visual estimate is usually made of humeral retroversion at operation, using the axis of the forearm, with the elbow flexed, and palpation of the humeral epicondyles. Retroversion was measured against these landmarks.

We used only the proximal half of the bone to define the axis of the shaft since this is where the prosthetic stem lies and, after trying a number of alternatives, the closest fitting and most reproducible model was a cylinder, the axis of which is a fair approximation to the location of the prosthetic shaft.

Another source of error was the selection of the datapoint values at the epicondyles. It may be possible in future to design a jig which could have more accurately located the required points for this study, and also at operation.

In order to reduce the influence of non-systematic (random) errors in the measuring procedure, the bones were measured three times. We found that approximately $10 \%$ of the spread could be attributed to random error the remaining $90 \%$ reflected biological variation. While it is accepted that there are significant sources of error due to the method of analysis in this study, there is no doubt that there is a significant posterior offset which could usefully be included in the specification of future prostheses.

If this offset of the humeral head is not incorporated in the design of prostheses, the instantaneous centre of rotation (Fischer et al 1977) will be moved and produce 
an abnormal mechanism in which the lever arm of muscles acting across the joint is altered. This relates particularly to the rotator cuff muscles whose moment would be altered by $20 \%$ if the centre of curvature were displaced by a distance equivalent to $20 \%$ of its radius. The syndrome of anterior coracoid impingement (Dines et al 1990) may occur in which the prosthesis contacts the lateral edge of the coracoid process. The normal clearance in the subcoracoid space has been estimated to be as little as $6.8 \mathrm{~mm}$ in the flexed shoulder (Gerber et al 1987). The normal posterior offset of $5 \mathrm{~mm}$ should therefore be preserved if possible.
This study reveals that part of what has previously been described as retroversion of the humeral head, is in fact posterior offset, and this should be considered by shoulder surgeons.

The authors wish to thank $\operatorname{Dr} \mathrm{N}$. Thomas, Acting Head of the Department of Human Morphology, and Mitutoyo (UK) Ltd for their technical assistance.

No benefits in any form have been received or will be received from a commercial party related directly or indirectly to the subject of this article.

\section{REFERENCES}

Amis AA, Dowson D, Unsworth A, Miller JH, Wright V. An examination of the elbow articulation with particular reference to variation of the carrying angle. Eng Med 1977; 6:76-80.

Campbell MJ, Gardner MJ. Calculating confidence intervals for some non-parametric analyses. $\mathrm{Br}$ Med J 1988; 296:1454-6.

Dines DM, Warren RF, Inglis AE, Pavlov H. The coracoid impingement syndrome. J Bone Joint Surg [ Br] 1990; 72-B:314-6.

Fischer LP, Carret JP, Gonon GP, Dimnet J. Étude cinématique des mouvements de l'articulation scapulo-humérale (Articulatio Humeri). Rev Chir Orthop 1977; 63(Suppl II):108-12.

Gerber C, Terrier F, Zehnder R, Ganz R. The subcoracoid space: an anatomic study. Clin Orthop 1987; 215:132-8.

Inman VT, Saunders JBdeCM, Abbott LC. Observations on the function of the shoulder joint. J Bone Joint Surg 1944; 28:1-30.
Kapandji IA. The physiology of the joints. Annotated diagrams of the mechanics of the human joints. Vol. 1. Edinburgh, etc: Churchill Livingstone, 1982.

Neer CS II. Articular replacemnt for the humeral head. $J$ Bone Joint Surg [ Am] 1955; 37-A :215-28.

Neer CS II. Replacement arthroplasty for glenohumeral osteoarthritis. J Bone Joint Surg [Am] 1974; 56-A:1-13.

Ovesen J, Sojbjerg JO, Sneppen O. A humeral head cutting guide: instrument to secure correct humeral component retroversion in shoulder joint arthroplasty. Clin Orthop 1987; 216:193-4.

Shiba R, Sorbie C, Siu DW, Bryant JT, Cooke TD, Wevers HW. Geometry of the humeroulnar joint. J Orth Res 1988; 6(6):897-906.

Williams PL, Warwick R. Gray's anatomy. Thirty-sixth edition. Edinburgh, etc: Churchill Livingstone, 1980: 359-62. 